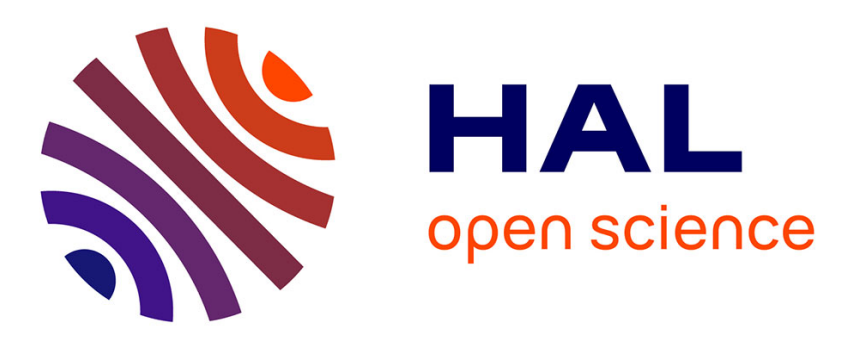

\title{
Tuning the release profile of ketoprofen from poly(l-lactic acid) suture using supercritical CO2 impregnation process
}

Mathilde Champeau, Isabela Trindade Coutinho, Jean-Michel Thomassin, Thierry Tassaing, Christine Jérôme

\section{To cite this version:}

Mathilde Champeau, Isabela Trindade Coutinho, Jean-Michel Thomassin, Thierry Tassaing, Christine Jérôme. Tuning the release profile of ketoprofen from poly(l-lactic acid) suture using supercritical CO2 impregnation process. Journal of Drug Delivery Science and Technology, 2020, 55, pp.101468. 10.1016/j.jddst.2019.101468 . hal-02990827

\section{HAL Id: hal-02990827 https://hal.science/hal-02990827}

Submitted on 17 Nov 2020

HAL is a multi-disciplinary open access archive for the deposit and dissemination of scientific research documents, whether they are published or not. The documents may come from teaching and research institutions in France or abroad, or from public or private research centers.
L'archive ouverte pluridisciplinaire HAL, est destinée au dépôt et à la diffusion de documents scientifiques de niveau recherche, publiés ou non, émanant des établissements d'enseignement et de recherche français ou étrangers, des laboratoires publics ou privés. 


\title{
Tuning the release profile of ketoprofen from poly(L-lactic acid) suture using supercritical $\mathrm{CO}_{2}$ impregnation process
}

\author{
Mathilde Champeau $^{\mathrm{a}, *}$, Isabela Trindade Coutinho ${ }^{\mathrm{a}}$, Jean-Michel Thomassin ${ }^{\mathrm{b}}$, Thierry Tassaing ${ }^{\mathrm{c}}$, \\ Christine Jérôme ${ }^{\mathrm{b}}$ \\ ${ }^{a}$ Center of Engineering, Modeling and Applied Social Sciences, Federal University of ABC, Santo André, SP, 09210-580, Brazi \\ ${ }^{\mathrm{b}}$ University of Liège, CESAM RU, Centre for Education and Research on Macromolecules (CERM), Sart-Tilman B6A, 4000, Liège, Belgium \\ ${ }^{\mathrm{c}}$ Institut des Sciences Moléculaires, UMR 5255 CNRS, University of Bordeaux, Groupe Spectroscopie Moléculaire, 351, Cours de la Libération, F-33405, Talence Cedex, \\ France
}

\section{A R T I C L E I N F O}

\section{Keywords:}

Supercritical carbon dioxide

Impregnation

Controlled release systems

Fiber

Anti-inflammatory drug

Hydrolysis

\begin{abstract}
A B S T R A C T
Poly(L-lactic acid) (PLLA) fibers were impregnated with the anti-inflammatory drug ketoprofen by supercritical $\mathrm{CO}_{2}\left(\mathrm{scCO}_{2}\right)$ assisted impregnation process, to develop drug-eluting absorbable sutures. This work indicates the possibility to tune not only the drug loading but also the release profile of ketoprofen from PLLA by modifying the impregnation (temperature and pressure) and depressurization (temperature and rate) conditions. Different PLLA sutures that release ketoprofen during 3 days up to 3 months were obtained. The release was shown to be governed by two parameters: the degradation rate of PLLA, that increases with the drug impregnation, and the sutures free volume, that was created due to $\mathrm{scCO}_{2}$ sorbed and was partially conserved during depressurization. The degradation rate and the tensile strength loss of the suture are accelerated by ketoprofen since it catalyzes PLLA acid hydrolysis.
\end{abstract}

\section{Introduction}

The supercritical carbon dioxide $\left(\mathrm{scCO}_{2}\right)$ assisted impregnation process has arisen as an interesting alternative to traditional processes to load a drug into a preformed polymer implant in order to transform it into a drug-eluting implant [1]. This process uses $\mathrm{CO}_{2}$ in supercritical state (above $31{ }^{\circ} \mathrm{C}$ and $7,38 \mathrm{MPa}$ ) as a solvent. $\mathrm{CO}_{2}$ can sorb in many semi-crystalline polymers, and can temporarily swell them and increase their free volume [2,3]. Moreover, $\mathrm{scCO}_{2}$ can solubilize a variety of drugs [4] and carry them into the swollen matrix resulting in the impregnation of the matrix. Using $\mathrm{scCO}_{2}$ enables the recovery of an impregnated polymer free of any solvent residues by depressurization after impregnation. Moreover, the supercritical conditions of $\mathrm{CO}_{2}$ being reached at reasonable temperature, this process can be applied to load thermosensitive drugs.

Due to these advantages, various polymer implants and medical devices have been impregnated with drugs to create drug-eluting implants $[1,5]$ such as lenses and subconjunctival implants [6,7], sutures $[8,9]$, scaffolds for tissue engineering [10-12] and endoprosthesis $[13,14]$ as recently reviewed [1].

It is well-known that the drug loading can be tuned by varying the operational conditions such as temperature, pressure, contact time and depressurization conditions [1]. The influence of each parameter on the drug loading has been intensively explored and many works focused on how to increase the drug loading by tuning the impregnation conditions [15-17]. Only few papers have been comparatively dedicated to exploring the potential of the $\mathrm{scCO}_{2}$ impregnation process to control the release of the drug by varying the process conditions [18-21]. Torres et al. [18] reported that an increase in the impregnation pressure results in the increase of the thymol diffusion coefficient when released from PLA into ethanol solutions of different concentrations. In the same study, the effect of the depressurization rate on the diffusion coefficient of thymol showed to be non-regular. Meanwhile, Rojas et al. [19] observed an increase in the diffusion coefficient when the depressurization rate was decreased or when the pressure were increased, on the release of 2-nonanone from linear low-density polyethylene (LLDPE) into an ethanol solution. In another work, Rojas et al. [20] observed no influence of the depressurization rate on the release of thymol from low-density polyethylene (LDPE) into ethanol solution. Milovanovic et al. [21] had also pointed out that the surface morphology created during the impregnation process has an impact on the release of thymol from cellulose acetate; in this study, conditions with higher

\footnotetext{
* Corresponding author.

E-mail addresses: mathilde.champeau@ufabc.edu.br (M. Champeau), isabela.coutinho@aluno.ufabc.edu.br (I.T. Coutinho), jm.thomassin@uliege.be (J.-M. Thomassin), thierry.tassaing@u-bordeaux.fr (T. Tassaing), c.jerome@uliege.be (C. Jérôme).
} 
impregnation yields resulted in pores on the surface that lead to a quicker release. In these papers, the release behavior was explained by small modifications or rearrangement of the polymer chains during the impregnation process. In the present work, we present an exploratory study that indicates the possibility to tune the drug release profile by adjusting the operational conditions during the $\mathrm{scCO}_{2}$ impregnation process and we rationalize the influence of the experimental conditions on the suture properties after the impregnation.

In a previous study, we have investigated the impregnation of three commonly implanted semi-crystalline polymer sutures made of poly-Llactide (PLLA), poly(ethylene terephthalate) (PET) and polypropylene (PP) with two non-steroid anti-inflammatory drugs, ketoprofen and aspirin. We explored the influence of the operational conditions such as time $(1 \mathrm{~h}-3 \mathrm{~h})$, temperature $\left(40-100{ }^{\circ} \mathrm{C}\right)$, pressure (10-35 MPa), depressurization rate $(0.06 \mathrm{MPa} / \mathrm{min}$ to high speed) and depressurization temperature $\left(-78\right.$ and $\left.80{ }^{\circ} \mathrm{C}\right)$ on the drug loading and on the tensile properties of the impregnated sutures [8]. The present work focuses of PLLA sutures impregnated with ketoprofen that have shown the largest range of drug loading (up to $32,5 \mathrm{wt} \%$ ) among the studied systems, and that was the only polymeric matrix from which the impregnated drug was released. Here, we evaluate the in vitro behaviors of these sutures to verify if they can be suitable as functional drug-eluting sutures. In case of absorbable sutures, their rate of tensile strength loss and the rate of absorption must match the healing speed of the tissues to respectively maintain their mechanical function and to avoid late complications. PLLA being an absorbable polymer, its degradation rate may evolve in vitro and in vivo due to the presence of the drug that can impact the absorption rate and its loss of tensile strength. Moreover, the drug release rate of the impregnated suture must be tuned to ensure a sustained release during the inflammation period, i.e. during 5-7 days [22].

First, the effect of the $\mathrm{scCO}_{2}$ impregnation treatment on the degradation rate and on the tensile strength loss was evaluated in vitro for the PLLA suture impregnated with ketoprofen. The respective effects of $\mathrm{CO}_{2}$ and drug on the degradation were determined by comparing the behavior of an impregnated suture with a suture only subjected to $\mathrm{scCO}_{2}$ in the same conditions of pressure, temperature, impregnation time and depressurization. Then, the effects of impregnation temperature $\left(80\right.$ and $\left.90{ }^{\circ} \mathrm{C}\right)$ and pressure $(30$ and $35 \mathrm{MPa})$ as well as the depressurization rate $(0.06 \mathrm{MPa} / \mathrm{min}$ and high speed) and temperature $\left(-78\right.$ and $\left.80{ }^{\circ} \mathrm{C}\right)$ on the ketoprofen release profiles from PLLA were evaluated. The results were rationalized regarding the drug impregnation, the coating and the free volume created in the PLLA sutures during the process. Based on our previous work [8], we have selected a set of conditions that result in a range of drug impregnation values (from 11.8 to $23.4 \%$ ) and impact the polymer microstructure (i.e. crystallinity) in a different extent while maintaining sufficient mechanical properties of the suture.

\section{Material and methods}

\subsection{Materials}

Carbon dioxide N45 (purity 99.95\%) was supplied by Air Liquide. PLLA monofilament suture was provided by Covidien. Ketoprofen, sodium nitrite $\left(\mathrm{NaNO}_{2}\right)$, sodium chloride $(\mathrm{NaCl})$, potassium chloride (KCl), sodium phosphate dibasic $\left(\mathrm{Na}_{2} \mathrm{HPO}_{4}\right)$, monopotassium phosphate $\left(\mathrm{KH}_{2} \mathrm{PO}_{4}\right)$, were purchased from Sigma-Aldrich and used as received.

\subsection{Supercritical impregnation process}

The impregnation of the fibers was performed in a batch process and a previously described protocol was applied [8]. $300 \mathrm{mg}$ of ground drug powder and a stirrer bar were added in a $40 \mathrm{~mL}$ stainless steel cell. This amount of drug ensured the saturation of $\mathrm{CO}_{2}$ with drug in all process conditions. A glass flask was placed above the stirrer bar, and about $60 \mathrm{mg}$ of suture was wind up and inserted in the flask. No filter was used to limit a possible drug deposition on the sutures surface during depressurization. Then, the high-pressure cell was placed into a thermostated bath heated up to the required temperature. A syringe connected to a high pressure-liquid pump (model 26D from Teledyne Isco) was used to load $\mathrm{CO}_{2}$ into the cell. When the desired pressure was reached, the system was kept at a given pressure and temperature, and the magnetic stirring was turned on (100 rpm). The impregnation time was $3 \mathrm{~h}$ since we have previously estimated that it is sufficient to reach the thermodynamic equilibrium [8] i.e. the drug solubilization in $\mathrm{scCO}_{2}$ [23] and the $\mathrm{scCO}_{2}$ sorption into the suture [3]. After the soaking time, the reactor was depressurized.

For the investigation of the degradation and the loss of tensile strength of impregnated PLLA suture, the PLLA fibers were impregnated at $75^{\circ} \mathrm{C}$ and $30 \mathrm{MPa}$ and quickly depressurized after dipping the reactor in an acetone/dry ice bath $\left(-78^{\circ} \mathrm{C}\right)$ for $10 \mathrm{~min}$. The process conditions were selected to obtain an intermediate drug impregnation (11.2\%) among the range of drug loadings of ketoprofen that we previously obtained in PLLA suture (that reached up to $32.5 \mathrm{wt} \%$ at $80{ }^{\circ} \mathrm{C}$ and $35 \mathrm{MPa}$ ) [8]. For the determination of $\mathrm{CO}_{2}$ effect on the PLLA degradation and on the tensile strength, samples were prepared by treating the suture with $\mathrm{scCO}_{2}$ at the same operational conditions but without the addition of ketoprofen.

For the study of the influence of the operational conditions on the ketoprofen release profile from PLLA, five PLLA fibers were impregnated in different conditions, varying the impregnation temperature $\left(80\right.$ and $\left.90{ }^{\circ} \mathrm{C}\right)$ and pressure (30 and $35 \mathrm{MPa}$ ) as well as the depressurization rate $(0.06 \mathrm{MPa} / \mathrm{min}$ and quick (c.a. $2 \mathrm{~s})$ ) and depressurization temperature $\left(-78\right.$ and $\left.80{ }^{\circ} \mathrm{C}\right)$. The fibers are named from $\mathrm{A}$ to $\mathrm{E}$ and the process conditions used for each one are reported in Table 1. The set of conditions have been chosen based on our previous results, considering that significant Drug Impregnations were obtained varying in the range, $11.8-23.4 \%$. The samples were prepared in triplicate.

As explained, different depressurization conditions were applied: the reactor was either dipped into an acetone/dry ice bath to quickly freeze the system at $-78{ }^{\circ} \mathrm{C}$ before a manual fast depressurization (fibers A, B and C); or quickly depressurized at $80^{\circ} \mathrm{C}$ (fiber D). The cooling of the reactor to $-78{ }^{\circ} \mathrm{C}$ led to the $\mathrm{CO}_{2}$ freezing and formation of dry ice that avoided the removal of the drug during the following rapid depressurization $(2 \mathrm{~s})$ of the residual gaseous $\mathrm{CO}_{2}$. The low depressurization rate $(0.06 \mathrm{MPa} / \mathrm{min})$ was performed by adding an automated valve (Top Industry) that controls the depressurization at the outlet of

Table 1

Experimental conditions used to prepare the five PLLA sutures impregnated with ketoprofen and their final characteristics.

\begin{tabular}{|c|c|c|c|c|c|c|}
\hline Sample & Impregnation conditions (T; P) & Depressurization conditions ( $\mathrm{T}$; rate)* & Diameter $(\mu \mathrm{m})$ & Drug Loading (\%) & Coating (\%) & Drug Impregnation (\%) \\
\hline A & $80{ }^{\circ} \mathrm{C} ; 30 \mathrm{MPa}$ & $-78^{\circ} \mathrm{C}$; quick & $228 \pm 13$ & $21.3 \pm 0.7$ & $3.0 \pm 0.2$ & $18.3 \pm 0.8$ \\
\hline B & $90{ }^{\circ} \mathrm{C} ; 30 \mathrm{MPa}$ & $-78{ }^{\circ} \mathrm{C}$; quick & $256 \pm 16$ & $23.9 \pm 0.8$ & $2.8 \pm 0.2$ & $21.1 \pm 0.3$ \\
\hline C & $80{ }^{\circ} \mathrm{C} ; 35 \mathrm{MPa}$ & $-78^{\circ} \mathrm{C}$; quick & $307 \pm 18$ & 28.9 & 5.5 & 23.4 \\
\hline $\mathrm{D}$ & $80{ }^{\circ} \mathrm{C} ; 30 \mathrm{MPa}$ & $80{ }^{\circ} \mathrm{C}$; quick & $191 \pm 8$ & 12.4 & 0.6 & 11.8 \\
\hline $\mathrm{E}$ & $80{ }^{\circ} \mathrm{C} ; 30 \mathrm{MPa}$ & $80{ }^{\circ} \mathrm{C} ; 0.06 \mathrm{MPa} / \mathrm{min}$ & $215 \pm 12$ & $33 \pm 2.6$ & $13.2 \pm 1.7$ & $19.8 \pm 0.9$ \\
\hline
\end{tabular}

* quick corresponds to a depressurization duration of $2-5 \mathrm{~s}$. 
the reactor.

During the quick depressurization at $80{ }^{\circ} \mathrm{C}$, the reactor was maintained at this temperature but it is worth pointing out that the real temperature inside the reactor may have decreased due to the JouleThomson effect. However, the real temperature has not been measured along the depressurization.

After depressurization, the fibers were kept in open petri dishes for a few hours and then stored in ziplock plastic bags at ambient temperature $\left(18-23{ }^{\circ} \mathrm{C}\right)$

\subsection{Characterization}

\subsubsection{In vitro degradation}

The degradation study was performed with three fibers: a raw PLLA fiber to serve as a reference; a PLLA fiber impregnated at $75{ }^{\circ} \mathrm{C}$ and $30 \mathrm{MPa}$ and quickly depressurized at $-78{ }^{\circ} \mathrm{C}$; and a PLLA fiber only subjected to $\mathrm{scCO}_{2}$ in absence of drug at $75^{\circ} \mathrm{C}$ and $30 \mathrm{MPa}$ and quickly depressurized at $-78{ }^{\circ} \mathrm{C}$. About $200 \mathrm{mg}$ of each suture was immersed into $50 \mathrm{~mL}$ of $1 \mathrm{M}$ phosphate buffered saline (PBS) solution at $37{ }^{\circ} \mathrm{C}$ in separated flasks. At each sampling time, about $40 \mathrm{mg}$ of each fiber was taken off, rinsed with distilled water and dried at room temperature before GPC analysis and tensile tests; and the PBS solution was totally replaced. The degradation study was carried out during 5 weeks.

\subsubsection{Gel Permeation Chromatography}

Gel Permeation Chromatography (GPC) was performed using the Malvern Viscotek TDA 305 model (Malvern Panalytical Ltd, United Kingdom). The molecular weight $\left(\mathrm{M}_{\mathrm{w}}\right)$ of the PLLA samples was determined by GPC in tetrahydrofuran (THF) using poly(styrene) standards at $45{ }^{\circ} \mathrm{C}$, at a flow rate of $0.7 \mathrm{~mL} / \mathrm{min}$, using the maximum of the peak. Ketoprofen was not removed before performing GPC.

\subsubsection{Tensile test}

The tensile properties of the sutures after immersion in PBS were measured with an electromechanical tensile tester (Instron model 5566, Elancourt, France). All fibers were mounted between holders at a distance of $2 \mathrm{~cm}$ (Pneumatic Action grips, Elancourt, France). Tensile testing was conducted at room temperature, at a rate of $5 \mathrm{~mm} \cdot \mathrm{min}^{-1}$. Three replicates were performed for each sample. The load is reported instead of stress since the diameters of the fibers were different and since, for the envisioned application, the fiber must resist to a given load.

\subsubsection{Drug loading}

The Drug Loading (DL) corresponds to the total mass of ketoprofen (impregnated and in the coating) per mass of PLLA fiber and was calculated according to:

Drug loading $(\%)=\frac{m_{\text {fiber after impregnation }}-m_{\text {raw fiber }}}{m_{\text {raw fiber }}} * 100$

where $m_{\text {fiber after impregnation }}$ is the weight of the impregnated suture fiber and $m_{\text {raw fiber }}$ is the weight of the initial raw suture fiber. The weights were measured with a balance Mettler Toledo XS 204 (precision $10^{-4} \mathrm{~g}$ ).

\subsubsection{Dissolution of the coating and mass contribution of the coating}

All the sutures were recovered with a coating made of ketoprofen precipitated on the suture surface. The time $t_{\text {coating }}$ necessary to totally dissolve the coating on each fiber was determined from the scanning electron microscope (SEM) images of sutures, that were immersed in $1 \mathrm{M}$ PBS at $37^{\circ} \mathrm{C}$ for different times.

Coating represents the percentage of loaded ketoprofen that forms the coating. Coating was determined by measuring the mass of ketoprofen forming the coating ( $m_{\text {coating }}$ ) from the drug release curves at $t_{\text {coating. }}$. We considered that the amount of drug that is released from the suture until $t_{\text {coating }}$ is only due to the dissolution of the coating and not to the release of the impregnated drug inside the suture, and that the suture does not absorb water during this period. Thus, Coating can be also expressed as:

Coating $(\%)=\frac{m_{\text {coating }}}{m_{\text {raw fiber }}} * 100$

where $m_{\text {coating }}$ is the weight of ketoprofen in the coating and $m_{\text {raw fiber }}$ is the weight of the initial raw suture fiber.

\subsubsection{Drug impregnation}

The Drug Impregnation corresponds to the mass of impregnated ketoprofen inside the PLLA suture (excluded the ketoprofen forming the coating) per mass of PLLA fiber and was calculated using equation (3):

Drug Impregnation $(\%)=$ Drug loading - Coating $=\frac{m_{\text {bulk }}}{m_{\text {raw fiber }}} * 100$

where $m_{\text {bulk }}$ is the weight of ketoprofen impregnated inside the PLLA and $m_{\text {raw fiber }}$ is the weight of the initial raw suture fiber.

The impregnated samples were weighted at least 5 days after the impregnation since preliminary tests have shown that $\mathrm{CO}_{2}$ was desorbed after that time and the mass remained constant.

\subsubsection{In vitro drug release}

The drug release experiments were performed in $1 \mathrm{M} \mathrm{PBS}$ at $37^{\circ} \mathrm{C}$. Between 7 and $10 \mathrm{mg}$ of impregnated fiber was immersed into $10 \mathrm{~mL}$ of PBS, the weight of the fiber being precisely determined. The coating of the impregnated fibers was not removed before the release experiment in order to study the release profile that can be obtained from the sutures as obtained directly after the process (with the coating and the impregnated drug). At predetermined time periods, $2 \mathrm{~mL}$ aliquot of the released solution were taken off and replaced by $2 \mathrm{~mL}$ of fresh PBS. The $2 \mathrm{~mL}$ were analyzed by UV-vis spectroscopy (HITACHI U-3300/ 130-0614, Japan) and the concentration of ketoprofen in the samples was measured at $259 \mathrm{~nm}$ for ketoprofen, using a previously performed calibration curve. The drug release experiments were performed in duplicate except for fibers $\mathrm{C}$ and $\mathrm{D}$.

In order to compare the release profile of fibers impregnated with different drug loadings, the cumulative drug release was calculated as the percentage of cumulative mass of drug released $M_{t}$ at time $t$ in relation to the Drug Loading:

Cumulative drug release $=100^{*} \frac{M_{t}}{\text { Drug Loading }}$

The Korsmeyer-Peppas model was used to analyze the drug release profile and to estimate the kinetic model and the release mechanism of drug from the fibers for the first $60 \%$ of cumulative drug release, using equation (5):

$\frac{M_{t}}{M_{\infty}}=k t^{n}$

where $M_{\infty}$ is the amount of impregnated drug released at infinite time (which corresponds to the mass of ketoprofen impregnated into PLLA), and $t$ the time (in hours). $n$ corresponds to the diffusional coefficient that is representative of the transport mechanism and $k$ is the kinetic constant. This equation can be applied to model the release of the present system since the drug diffuses in only one dimension as the length/thickness ratio of the fibers is above 10 [24]. The mechanism responsible for the drug loading is evaluated from the value of the diffusional coefficient $n$. For a cylindrical matrix, $n \leq 0.45$ corresponds to Fickian diffusion, $0.45<n<0.89$ to a anomalous transport due to diffusion and degradation of the polymer, $n=0.89$ to case II transport, and $n>0.89$ to super case II transport.

\subsubsection{Fiber morphology imaging}

The morphology of the fibers was observed by SEM using a JEOL 
JSM 840-A microscope after metallization with Pt (30 nm).

\subsubsection{Diameter of the fibers}

The diameter of the impregnated fibers used in the drug release study was measured with a micrometer at five different places along each fiber, at $t_{\text {coating }}$ i.e. once the coating had been removed. The average of the diameter was calculated.

\subsubsection{Drug distribution by Raman imaging}

The impregnated fibers were cut perpendicularly to their length, and their coating was not removed prior to measurement. The drug distribution was evaluated on the cross section of the fibers by Raman imaging. A confocal Raman system (Labram II, Horiba Jobin-Yvon, Japan), with a $633 \mathrm{~nm}$ excitation wavelength was used, with a 20x objective. A spectrum was recorded each $10 \mu \mathrm{m}$ in X and Y directions. The Raman imaging were obtained from the ratio of the Raman bands of ketoprofen (bands centered at 1598 and $1658 \mathrm{~cm}^{-1}$ ) and PLLA (band centered at $1450 \mathrm{~cm}^{-1}$ ). The band of PLLA was chosen since it is independent on PLLA degradation. All the Raman images have identical color scales.

\section{Results and discussion}

\subsection{Degradation study of PLLA sutures}

The properties of absorbable sutures such as PLLA evolve in vitro and in vivo as a consequence of their degradation. The chemical degradation of degradable polyester sutures such as PLLA happens through hydrolysis of the ester bonds in its amorphous regions. The cleavage of the ester bonds results in the decrease of the molecular weight and the regression of the tensile properties.

In biomedical engineering, two terms are distinguished for absorbable sutures: the rate of absorption and the rate of tensile strength loss. The rate of absorption of the suture has to match the healing speed of the tissue on which the suture is implanted to avoid any late complications [25], the healing speed being specific for each tissue. The rate of tensile strength loss impacts the function of the suture that is to mechanically ensure an adequate proximity of the wound edges during the healing process of the tissues [26].

The in vitro evolution of molecular weight and tensile strength with incubation time in $1 \mathrm{M}$ PBS at $37{ }^{\circ} \mathrm{C}$ have been compared for three fibers: the raw commercial PLLA suture, a PLLA suture impregnated with ketoprofen and a fiber only subjected to $\mathrm{scCO}_{2}$. The impregnated suture was impregnated at $75{ }^{\circ} \mathrm{C}$ and $30 \mathrm{MPa}$ during $3 \mathrm{~h}$ and quickly depressurized at $-78{ }^{\circ} \mathrm{C}$. This suture resulted in a Drug Impregnation value of $11.2 \%$ and a Coating of $1.2 \%$ that was removed before the characterizations. The suture only subjected to $\mathrm{scCO}_{2}$ was prepared in the same conditions but without ketoprofen.

\subsubsection{Evolution of the molecular weight}

The evolution of the molecular weight of PLLA in function of the immersion time in PBS for the three sutures is reported in Fig. 1. The impregnated suture had a Drug Impregnation value of $11.2 \%$ and a Coating of $1.2 \%$ that was removed before the characterizations.

The degradation of PLLA is not disturbed by the $\mathrm{scCO}_{2}$ treatment since the molecular weights of the raw suture and the one only subjected to $\mathrm{CO}_{2}$ are similar and both exhibit a decrease of $20 \%$ of their initial molecular weight after 5 weeks of immersion.

The initial molecular weight of the impregnated PLLA is $30 \%$ smaller than the PLLA only subjected to $\mathrm{ScCO}_{2}$, indicating that the presence of ketoprofen has induced some PLLA degradation during the impregnation process. Once immersed in PBS, the molecular weight strongly decreases during 5 weeks, being 85\% smaller when compared to the raw PLLA suture at the same time. The measurements were stopped after 5 weeks, but it is expected that the molecular weight continues to decrease with time.

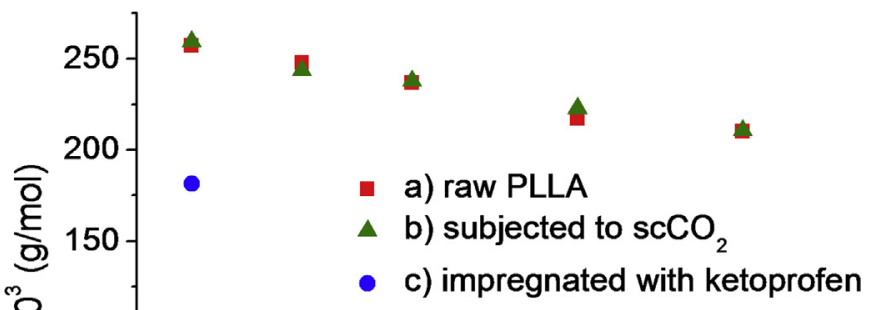

1. Evolution of PLLA molecular weight in function of the immersion time in PBS for a) raw PLLA (squares); b) PLLA subjected to $\mathrm{scCO}_{2}$ (triangles); and c) PLLA impregnated with ketoprofen (Drug Impregnation $=11.2 \%$ ) (circles).<smiles>CC(C(=O)O)c1cccc(C(=O)c2ccccc2)c1</smiles>

b)

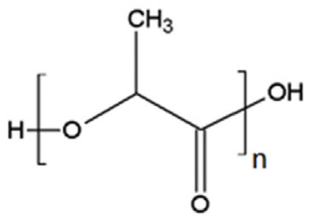

Fig. 2. Chemical Structure of a) Ketoprofen and b) PLLA.

Ketoprofen (Fig. 2a) is a molecule that bears one carboxylic acid function which, impregnated into PLLA and in presence of PBS, can accelerate the hydrolysis of the ester bonds of PLLA (Fig. 2b) and its degradation. Even if ketoprofen is released from the matrix with time, the short chains resulting in the degradation of PLLA possess acidic function at their chain ends that catalyzes the hydrolysis [24,27].

Moreover, a higher diameter of the impregnated fiber is associated to a higher free volume that facilitates the diffusion of water that induces hydrolysis into the PLLA matrix, as further explained in section 3.2.3. Indeed, the diameter of raw suture is $150 \mu \mathrm{m}$, whereas the diameter of the one just subjected with $\mathrm{scCO}_{2}$ is about $170 \mu \mathrm{m}(13 \%$ higher) and the one of the suture impregnated with ketoprofen is about $187 \pm 5 \mu \mathrm{m}$ ( $\sim 25 \%$ higher $)$.

Since the degradation of an absorbable suture must match the healing speed of the tissue on which it is implanted, the application of the PLLA sutures impregnated with ketoprofen by $\mathrm{scCO}_{2}$-assisted impregnation must be adapted to tissues with a faster healing process than the ones repaired with the raw PLLA fibers [28].

\subsubsection{Loss of tensile properties}

Fig. 3 shows the evolution of the load-strain curves with immersion time in PBS of the three studied fibers. The tensile properties of the raw commercial suture (Fig. 3a) and of the suture subjected to $\mathrm{scCO}_{2}$ (Fig. 3b) are initially different due to the impact of the $\mathrm{CO}_{2}$ pressurization/depressurization treatment on the PLLA microstructure [8] but do not change during 5 weeks. On the contrary, the load-strain curve of the suture impregnated with ketoprofen (Fig. 3c) undergoes dramatic changes after one week in PBS and the suture totally loses its tensile strength after 3.5 weeks due to its accelerated degradation. The plastic domain is more impacted than the elastic one, but the tensile yield strength remains the same. The ultimate strength decreases up to $75 \%$ after 3.5 weeks while the Young modulus tends to slightly increase with the degradation time in PBS (see supporting information a).

This loss of tensile strength is comparable to other absorbable 
a)

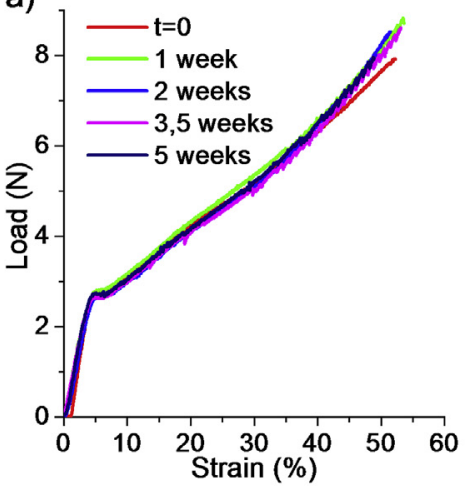

b)

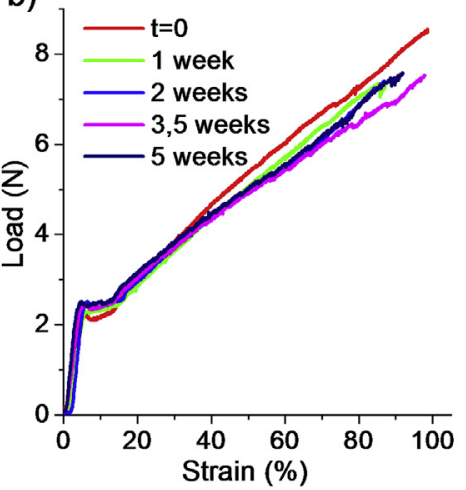

c)

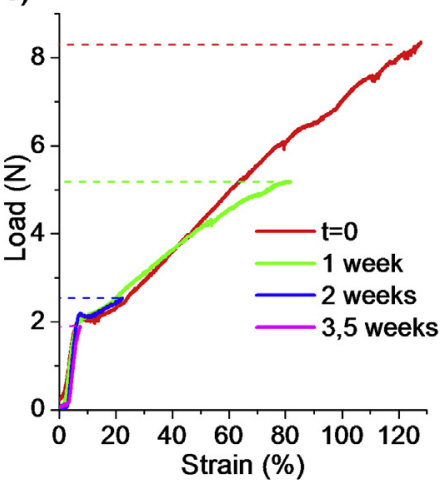

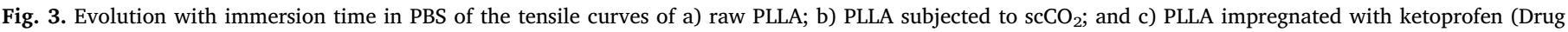
Impregnation $=11.2 \%$ ).

sutures. For instance, Caprosyn ${ }^{\mathrm{Tm}}$, a monofilament composed of glycolide, caprolactone, trimethylene carbonate and lactide, losses its original tensile strength after 3 weeks of implantation in vivo. The applications of Caprosyn ${ }^{\mathrm{TM}}$ sutures include general soft tissue approximation and/or ligation [29]. Our impregnated PLLA can then be used in similar application as Caprosyn ${ }^{\mathrm{TM}}$. To avoid such a fast loss of tensile strength, a PLLA fiber with a higher original molecular weight could be used to enlarge the applicability range and to create drug-eluting sutures for tissues that heal more slowly. Another possibility should be to impregnate a drug that does not possess acidic function in order to avoid the faster degradation of PLLA.

\subsection{In vitro drug release of impregnated PLLA sutures}

The possibility to tune the drug release profile of a drug impregnated into a polymer by varying the impregnation and/or depressurization conditions was investigated. Five PLLA fibers were impregnated with ketoprofen in different conditions of impregnation and depressurization that are reported in Table 1 . The diameter, the \% Drug Loading, Coating, and the \% Drug Impregnation are also listed in Table 1, for each impregnated fiber.

As it has been previously reported in the literature, the $\mathrm{scCO}_{2} \mathrm{im}$ pregnation process can lead to the formation of a coating on the surface of the polymer $[8,30]$. The release study has been carried out with the sutures as obtained after the process, without removal of the coating.

The process conditions may also impact the release of the impregnated drug. In section 3.1., it has been highlighted that a drug bearing carboxylic acid function can catalyze the hydrolysis of an absorbable polymer such as PLLA, the speed of degradation being expected to be dependent on the Drug Impregnation of such a drug. Moreover, the process conditions may change the free volume of the polymer and the diffusion of the drug through the matrix.

\subsubsection{Coating characterization}

The coatings composed of ketoprofen on the five sutures have been characterized in terms of morphology, homogeneity and rate of dissolution in $1 \mathrm{M}$ PBS at $37{ }^{\circ} \mathrm{C}$, by SEM images (Fig. 4). Three morphologies of coating were observed, that varied with the depressurization conditions. The time $t_{\text {coating }}$ necessary to totally dissolve each kind of coating was evaluated by SEM images of fragments of each fiber, after different period of time of immersion of the fibers in PBS (see supporting information $b$ ).

In the case of fibers that were cooled at $-78{ }^{\circ} \mathrm{C}$ before depressurization (fibers A, B and C), a homogeneous and non-friable coating was observed. Ketoprofen crystallized in needle-shaped crystals (Fig. 4a and b). This coating is formed from the drug solubilized in surrounding $\mathrm{scCO}_{2}$ that precipitated during the cooling step [31]. The Coating is c.a. $2,8-5,5 \%$ in the three samples.
The sutures that were subjected to a quick depressurization at $80{ }^{\circ} \mathrm{C}$ (fiber D) exhibited a thin homogeneous coating made of packed platelets (Fig. 4c and d). The amount of drug in the coating is small (Coating $=0,6 \%$ ). During the quick depressurization, the drug is quickly vented with $\mathrm{CO}_{2}$ due to flow dragging. The precipitation of ketoprofen from surrounding $\mathrm{CO}_{2}$ should be minimal and, the coating may arise from ketoprofen that was inside the fiber and was extracted during venting.

Finally, a third kind of coating was observed on the sutures that were slowly depressurized at $80{ }^{\circ} \mathrm{C}$ (fiber E). A heterogeneous coating composed of partially crystallized ketoprofen can be noticed on Fig. 4e and $\mathrm{d}$. This coating was friable and could be partially removed during handling. Since the depressurization speed was slow, ketoprofen was not dragged by $\mathrm{CO}_{2}$ but instead it precipitated in the high-pressure cell due to the slow decrease of its solubility from $7.2 * 10^{-4} \mathrm{M}$ fraction at $80{ }^{\circ} \mathrm{C}$ and $30 \mathrm{MPa}$ up to zero at atmospheric conditions [23]. Consequently, it precipitated and accumulated progressively on the upper side of the suture, creating an irregular and thick coating (Coating of $13.2 \%)$.

The dissolution rate of the coatings can be influenced by their thickness and by the polymorphic form of ketoprofen [32-34]. Two polymorphic forms of ketoprofen exist: a regular crystalline one and a second amorphous one that is metastable $[35,36]$. The first coating may correspond to the crystalline one. However, it is difficult to clearly determine in which crystalline state is ketoprofen in the second and third coatings.

The first coating was totally solubilized after $t_{\text {coating }}=5 \mathrm{~min}$. Normally, the crystalline form of ketoprofen solubilizes more slowly than the amorphous one, but the observed quick dissolution may be accounted by the high surface area of the needles and porosity of the coating [37]. The second coating (fiber D) was totally dissolved after $4 \mathrm{~h}$ due to the lower surface area of the ketoprofen plate-shaped coating. The thicker coating formed on fiber $\mathrm{E}$ lasted $5 \mathrm{~h}$ to totally dissolved, probably due to its higher thickness and high density in localized regions.

During storage of the samples at room temperature $\left(18-23{ }^{\circ} \mathrm{C}\right)$, the diffusion of ketoprofen from the coating to the polymer top layer may have occurred, driven by the difference of ketoprofen concentration between the two regions. Nonetheless, this diffusion is probably limited by the low mobility of the polymeric chains at room temperature. For example, the glassy temperature of PLLA sutures impregnated with $21 \mathrm{wt} \%$ of ketoprofen is c.a. $38^{\circ} \mathrm{C}$ which highlights the restricted chains mobility in storage conditions [8]. We have estimated that this diffusive phenomenon during storage occurred similarly in all the samples regardless of their drug impregnation (in all the samples, ketoprofen concentration was superior in the coating in comparison to the polymer phase) and that this phenomenon may affect in a slight extent the amount of drug within the coating (Coating) and within the suture (\% 

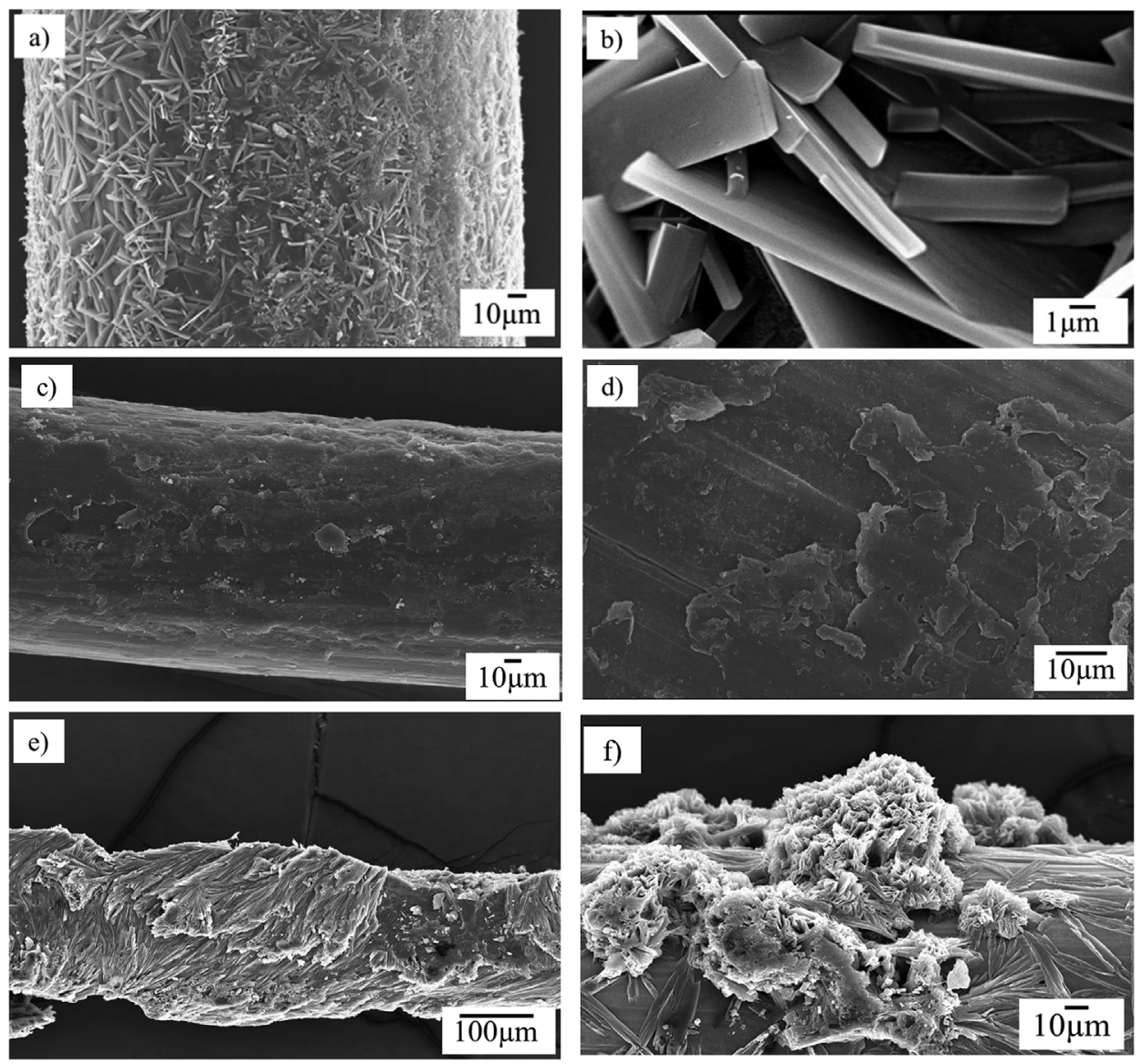

Fig. 4. SEM images of a) and b) first kind of coating of ketoprofen observed on fibers $\mathrm{A}, \mathrm{B}$ and $\mathrm{C}$ that were cooled at $-78{ }^{\circ} \mathrm{C}$ before quick depressurization; c) and d) of the second kind of observed on fiber $\mathrm{D}$ that was depressurized at $80{ }^{\circ} \mathrm{C}$ during $2 \mathrm{~s}$; e) and $\mathrm{f}$ ) third kind of coating observed on fiber $\mathrm{E}$ that was depressurized at $80{ }^{\circ} \mathrm{C}$ at a depressurization rate of $0.06 \mathrm{MPa}$ / $\min$.
Drug Impregnation) along the storage time.

In this work, no protection was used to prevent the coating formation by drug precipitation. If a physical protection had been used, the precipitation of the solubilized drug in the surrounding $\mathrm{scCO}_{2}$, as observed in fibers A, B, C and E, would not occur on the fiber surface and no coating would be formed by this process. However, the coating still could be formed due to the drug being dragged out the matrix and precipitating at its surface, as it was seen in fiber D.

\subsubsection{Drug impregnation}

The Drug Impregnation that corresponds to the mass of drug impregnated into the matrix per mass of polymer was calculated using equation (3). As shown in Table 1, the Drug Impregnation of ketoprofen in PLLA depends on the impregnation conditions. $\mathrm{scCO}_{2}$-assisted impregnation process is governed by mass transfer and thermodynamics. The drug solubility in $\mathrm{scCO}_{2}$, the $\mathrm{CO}_{2}$ sorption into PLLA and polymer swelling are impacted by temperature and pressure. The mass transfer of ketoprofen from the $\mathrm{CO}_{2}$-phase to the fiber is a diffusion process facilitated by an increase of $\mathrm{CO}_{2}$ sorption and swelling. In accordance to already reported data [8], Drug Impregnation rises with temperature (comparison of fibers A and B) and pressure (comparison of A and C). In the range of investigated pressures (above the ketoprofen crossover pressure), the solubility of ketoprofen in $\mathrm{CO}_{2}$ rises with temperature due to its higher sublimation pressure, increasing from $5 * 10^{-4}$ to $7.2 *$ $10^{-4} \mathrm{~mol}$ fraction when the temperature is increased from $80{ }^{\circ} \mathrm{C}$ to $90{ }^{\circ} \mathrm{C}$ at $30 \mathrm{MPa}$ [23]. Moreover, the $\mathrm{CO}_{2}$ sorption and PLLA swelling increase between $80^{\circ} \mathrm{C}$ and $90^{\circ} \mathrm{C}$ as temperature get closer to the in situ melting temperature of PLLA $\left(\approx 100{ }^{\circ} \mathrm{C}\right)$ impregnated with ketoprofen. To the best of our knowledge, there are no data of $\mathrm{CO}_{2}$ sorption and PLLA swelling reported in the literature at these temperatures. However, at such temperatures, Differential Scanning Calorimetry proved elsewhere that a partial melting of the PLLA crystals occurs during its impregnation with ketoprofen due to an increase in the chain mobility caused by the interaction between the $\mathrm{scCO}_{2}$, the ketoprofen and the polymer, a phenomena known as a cryogenic effect of the $\left\{\mathrm{scCO}_{2}+\right.$ ketoprofen $\}$ mixture [8]. That results in an increase of the proportion of amorphous domains that probably allows more $\mathrm{CO}_{2}$ to be absorbed in PLLA and a higher swelling of the fibers [3]. These phenomena favor the diffusion of the $\left\{\mathrm{CO}_{2}+\right.$ ketoprofen $\}$ mixture in the fiber, thus resulting in higher Drug Impregnation. Under isothermal conditions, an increase of pressure provokes an increase in the Drug Impregnation which is associated to an increase of $\mathrm{CO}_{2}$ density and its solvating power, thus improving ketoprofen solubility. At $80{ }^{\circ} \mathrm{C}$, ketoprofen solubility rises from $5 * 10^{-4}$ to $7 * 10^{-4} \mathrm{~mol}$ fraction when the pressure is increased from 30 to $35 \mathrm{MPa}$ [23]. Moreover, $\mathrm{CO}_{2}$ sorption in PLLA and polymer swelling are also favored by pressure [3,38].

The temperature and speed of depressurization also impact the Drug Impregnation. Cooling the sample at $-78{ }^{\circ} \mathrm{C}$ before depressurization enables to freeze the system and to trap the drug inside the PLLA matrix. In that way, no drug is lost during depressurization of fibers A, B and $C$ and Drug Impregnation varying between 18.3 and $23.4 \%$ are achieved. However, a quick depressurization at $80{ }^{\circ} \mathrm{C}$ leads to mechanically drag out the drug with $\mathrm{CO}_{2}$ during the venting, the Drug Impregnation of fiber D is thus lower than the one of fiber A. This extraction effect is hindered by reducing the depressurization rate like in the case of fiber $\mathrm{E}\left(0.06 \mathrm{MPa} / \mathrm{min} ; 80{ }^{\circ} \mathrm{C}\right)$. The retention of ketoprofen in PLLA at slow depressurization rate is accounted by the high affinity of ketoprofen and PLLA [8] that interact through strong H-bonds [3].

\subsubsection{Free volume}

The free volume of the fiber can also have a strong impact on the drug release profile since the buffer and the drug can more easily diffuse through the matrix if the cavities formed by the free volume are at least equal or larger than the volume of the ketoprofen molecule. The 


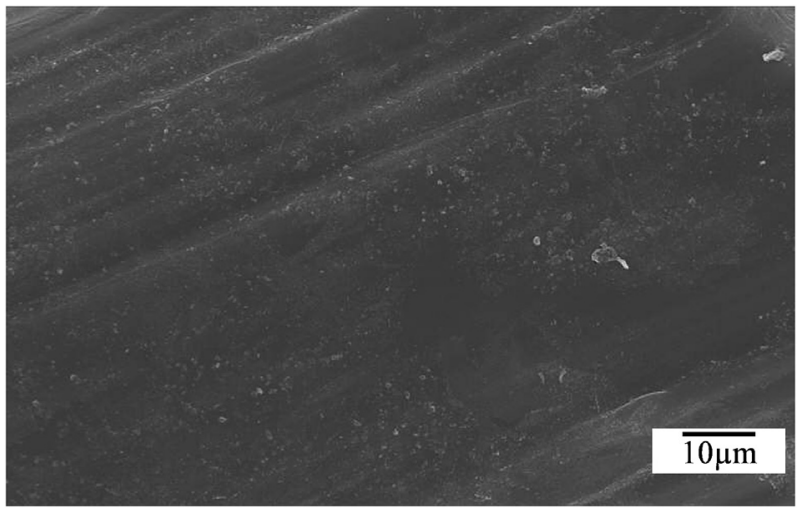

Fig. 5. SEM images of fiber D that was impregnated at $80{ }^{\circ} \mathrm{C}$ and $30 \mathrm{MPa}$ and depressurized at $80{ }^{\circ} \mathrm{C}$ during $2 \mathrm{~s}$, after coating removal. No evidence of foaming can be observed.

increase in the fibers diameter after impregnation (Table 1) has been used to estimate their free volume considering that the diameter of the raw PLLA fiber is originally $150 \pm 3 \mu \mathrm{m}$. Indeed, this increase can be the result of three phenomena, i.e., the presence of ketoprofen molecules within the fiber, the increase of free volume due to the processing, and the presence of pores due to the polymer foaming entailed by $\mathrm{CO}_{2}$.

The polymer foaming contribution to the free volume can be discarded by the SEM analysis since no macroporosity has been observed. Among the processing conditions that have been explored, the one used for fiber D are favorable for polymer foaming (high depressurization temperature and quick depressurization) [39]. However, as shown in Fig. 5, no macroporosity is evidenced on the SEM images of the surface of fiber D after coating removal. The surface of the other samples after coating removal was also analyzed (not shown here) and led to the same conclusion.

The highest diameters have been observed for fibers A, B and C, i.e. fibers depressurized after freezing the impregnated fibers at $-78{ }^{\circ} \mathrm{C}$. The Tg of PLLA is about $61{ }^{\circ} \mathrm{C}$ under atmospheric pressure and can decrease in situ due to plasticizing effect of $\mathrm{CO}_{2}$ and ketoprofen $[3,40,41]$. Therefore, in these conditions, the temperature falls below the $\mathrm{T}_{\mathrm{g}}$ of PLLA while $\mathrm{CO}_{2}$ is still present inside the fibers. The frozen polymer cannot reorganize during depressurization and the free volume created by the sorbed $\mathrm{CO}_{2}$ during the impregnation is partially conserved. The diameter of these three fibers increases when the impregnation conditions favor $\mathrm{CO}_{2}$ sorption in the polymer, i.e. higher temperature and higher pressure [1].

It is worth noting that the presence of the drug tends to increase the free volume created during the process since lower increase of the diameter has been observed for fibers only subjected to $\mathrm{CO}_{2}$ in the same experimental conditions: $174 \pm 4 \mu \mathrm{m}$ at $80^{\circ} \mathrm{C}$ and $30 \mathrm{MPa}$ (compared to $228 \pm 13 \mu \mathrm{m}$ in fiber A) and $190 \pm 3 \mu \mathrm{m}$ at $90{ }^{\circ} \mathrm{C}$ and $30 \mathrm{MPa}$ (compared to $256 \pm 16 \mu \mathrm{m}$ in fiber B), both quickly depressurized at $-78{ }^{\circ} \mathrm{C}$. Ketoprofen acts as a cryogenic agent and induces a melting/ recrystallization process in this range of temperatures that consequently increases the $\mathrm{CO}_{2}$ sorption and the swelling of the PLLA matrix [3,42].

Fibers $\mathrm{D}$ and $\mathrm{E}$ have been depressurized at $80{ }^{\circ} \mathrm{C}$. This temperature being above the $\mathrm{T}_{g}$ of PLLA, the chains can reorganize during the depressurization step. Besides, the depressurization rate impacts the restructuration of the polymer that was swollen by $\mathrm{scCO}_{2}$. In case of fiber $\mathrm{D}$, the quick venting of $\mathrm{CO}_{2}$ as well as the partial mechanical dragging of ketoprofen leads to the decrease of the polymer swelling and the final fiber exhibits a small diameter $(191 \pm 8 \mu \mathrm{m})$ and, a poor free volume fraction. The higher diameter of fiber $\mathrm{E}$ in respect to fiber $\mathrm{D}$ can be explained by the higher drug impregnation.

\subsubsection{Drug release profiles}

The drug release profiles of the five PLLA sutures impregnated with

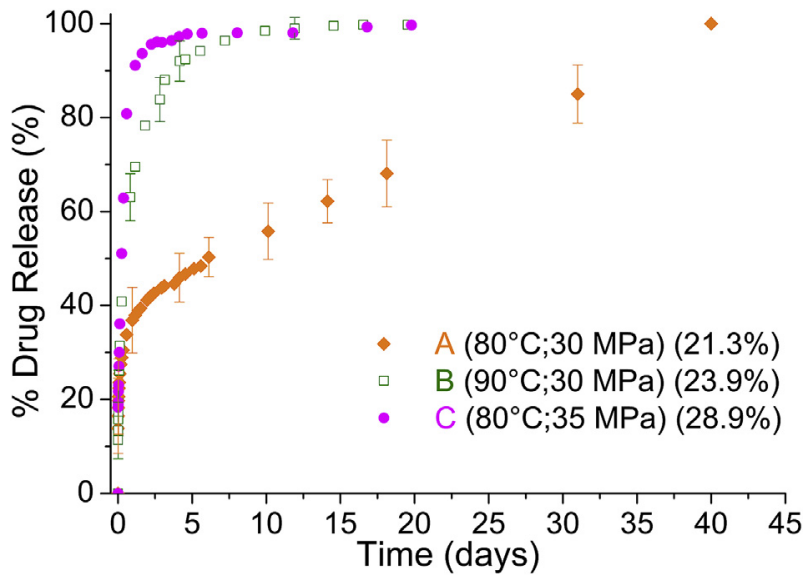

Fig. 6. Comparison of the drug release profiles of PLLA fibers (A, B and C) impregnated. at different pressure and temperature (in parenthese is reported the temperature and the depressurization rate; and in square bracket is reported the drug loading).

ketoprofen have been measured (Figs. 6, 8 and 9). Varying the conditions of the process not only impacts the drug loading but also influences the release profile. Some fibers exhibit a sustained release profile up to 3 months (fiber D; Fig. 8) whereas other fibers release all the drug after 3 days (fiber C; Fig. 6). In all the release profiles, a first burst release occurs which is due to the dissolution of the coating of ketoprofen and that lasts between $5 \mathrm{~min}$ and $5 \mathrm{~h}$ depending on the kind of coating. This burst release due to the coating would permit an immediate anti-inflammatory effect after the implantation of the sutures.

3.2.4.1. Influence of the impregnation conditions on the drug release. The faster release occurs for fibers $\mathrm{A}, \mathrm{B}$ and $\mathrm{C}$ in the following order: $\mathrm{C}>\mathrm{B}>\mathrm{A}$ (Fig. 6). The loaded drug is totally released after 3 days in case of fiber $\mathrm{C}$ whereas fiber A releases only $50 \%$ of its Drug Loading after 10 days. The coating of these three fibers exhibiting a similar morphology, solubility and amount, it cannot explain these differences. However, two main parameters can account for these results: the free volume and the degradation rate of PLLA.

Indeed, the release kinetic is dependent on the diameter and, consequently, on the free volume of the fibers. The higher is the free volume and the faster is the diffusion of the buffer into PLLA and the diffusion of ketoprofen towards the buffer media. Consequently, conditions that favor the increase of free volume result in a quick release of ketoprofen from PLLA, which is the case of fiber C.

The Drug Impregnation tends also to increase the drug release rate. The acceleration of the hydrolysis of PLLA by the increase in ketoprofen impregnation can account for this observation, as observed in section 3.1. Unfortunately, from these results alone, it is not possible to determine which one of the two parameters has the highest impact on the drug release profile.

Raman imaging were performed on the cross-section of the fibers after determined times to understand the ketoprofen release. The distribution of ketoprofen on the cross-section of fiber $\mathrm{C}$ along the drug release is shown in Fig. 7. Although a peripheral zone appears to be depleted of ketoprofen after $30 \mathrm{~min}$, the drug is released from all the parts of the fiber, meaning that PBS diffused into the inner part of the fiber. After $20 \mathrm{~h}, 80 \%$ of the drug is released and after 3 days, only traces of ketoprofen can be observed confirming the almost total release.

Since the release profile of fiber $C$ stops after 3 days, this impregnated suture would not match the inflammation duration requires a release over 5-7 days. However, fiber A and B would fulfill this requirement. 


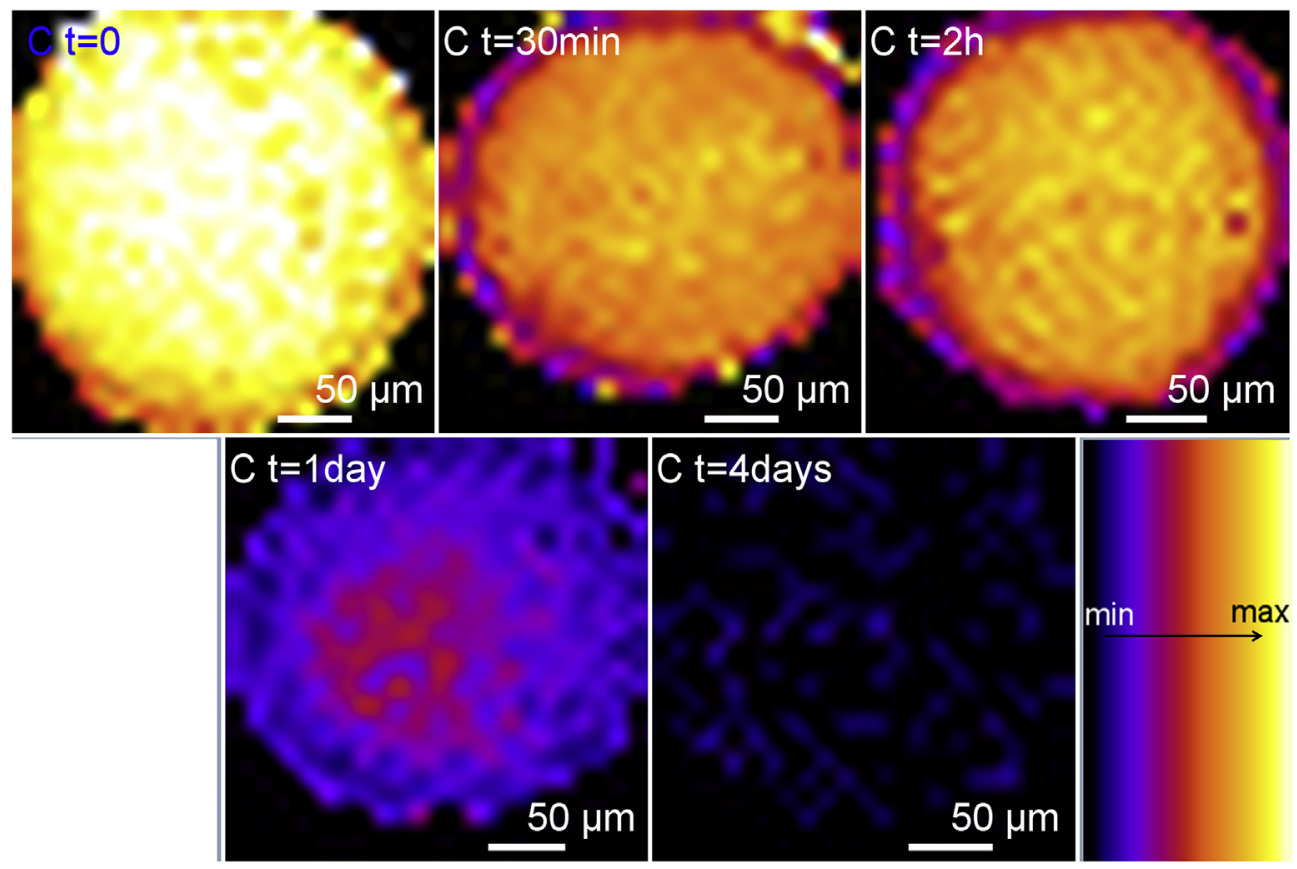

Fig. 7. Raman imaging showing the distribution of ketoprofen on the cross-section of fiber C during drug release.

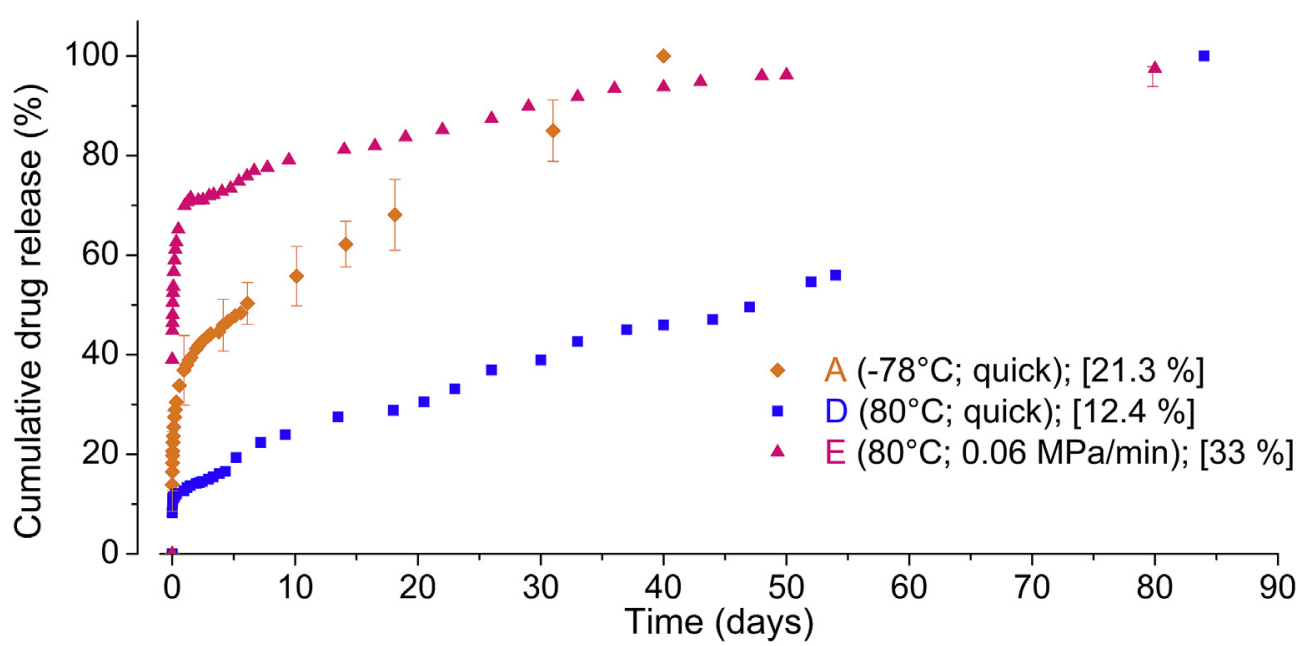

Fig. 8. Effect of depressurization conditions on drug release profile; comparison of the drug release profiles of fibers A, D and E (in bracket is reported the drug content). The dash lines are presented as a guide for the eyes.

3.2.4.2. Influence of depressurization conditions on the drug release. The influence of depressurization conditions on the ketoprofen release profile is highlighted by comparing fibers $\mathrm{A}, \mathrm{D}$ and $\mathrm{E}$ that have been depressurized at different temperatures and different depressurization rates (Fig. 8).

The burst releases during the early release time are concordant with the presence of the coatings and their progressive dissolution. Fiber $\mathrm{E}$ exhibits the most significant burst release due to the important contribution of the coating to the Drug Loading (Coating of 13.2\%) that is released during the first $5 \mathrm{~h}$.

In order to compare the release of the drug impregnated into the three sutures, the contribution of the coating has been subtracted to the release profiles and the results are shown in Fig. 9 where the time $t=0$ corresponds to the time $t_{\text {coating }}$ at which all the coating has been solubilized in PBS.

The drug release kinetic coefficients corresponding to the release of the impregnated ketoprofen were determined. The first $60 \%$ of drug release of Fig. 9 was fitted with the Korsmeyer-Peppas model, (Equation
(5)). The parameters $n$ and $k$ are listed in Table 2.

The kinetic of release and the percentage of released ketoprofen are similar for fibers A and E during the first 5 days. Similar amount of ketoprofen remains in the two matrices after 5 days as proved by Raman mapping, Fig. 9. The diffusional coefficient $n$ of samples A and $\mathrm{E}$ are similar. The values of $n$ are characteristic of a Fickian diffusion mechanism $(<0.45)$ [43], meaning that ketoprofen release is governed by diffusion during the first days. However, the significant degradation of PLLA after few days must contribute to the release at longer time. The similar drug release profiles of fiber $\mathrm{A}$ and $\mathrm{E}$ are explained by their similar Drug Impregnation and their similar free volume (similar diameters).

The release of fiber $\mathrm{D}$ is slower with respect to the one of $\mathrm{A}$ and $\mathrm{E}$. The diffusional coefficient $(0.45<n<0.89)$ suggests that ketoprofen is released by a combination of drug diffusion of matrix degradation. The diameter of this fiber is lower so the structure is more narrowly packed and the free volume is lower which hinders the quick diffusion of ketoprofen. Ketoprofen is progressively released during 


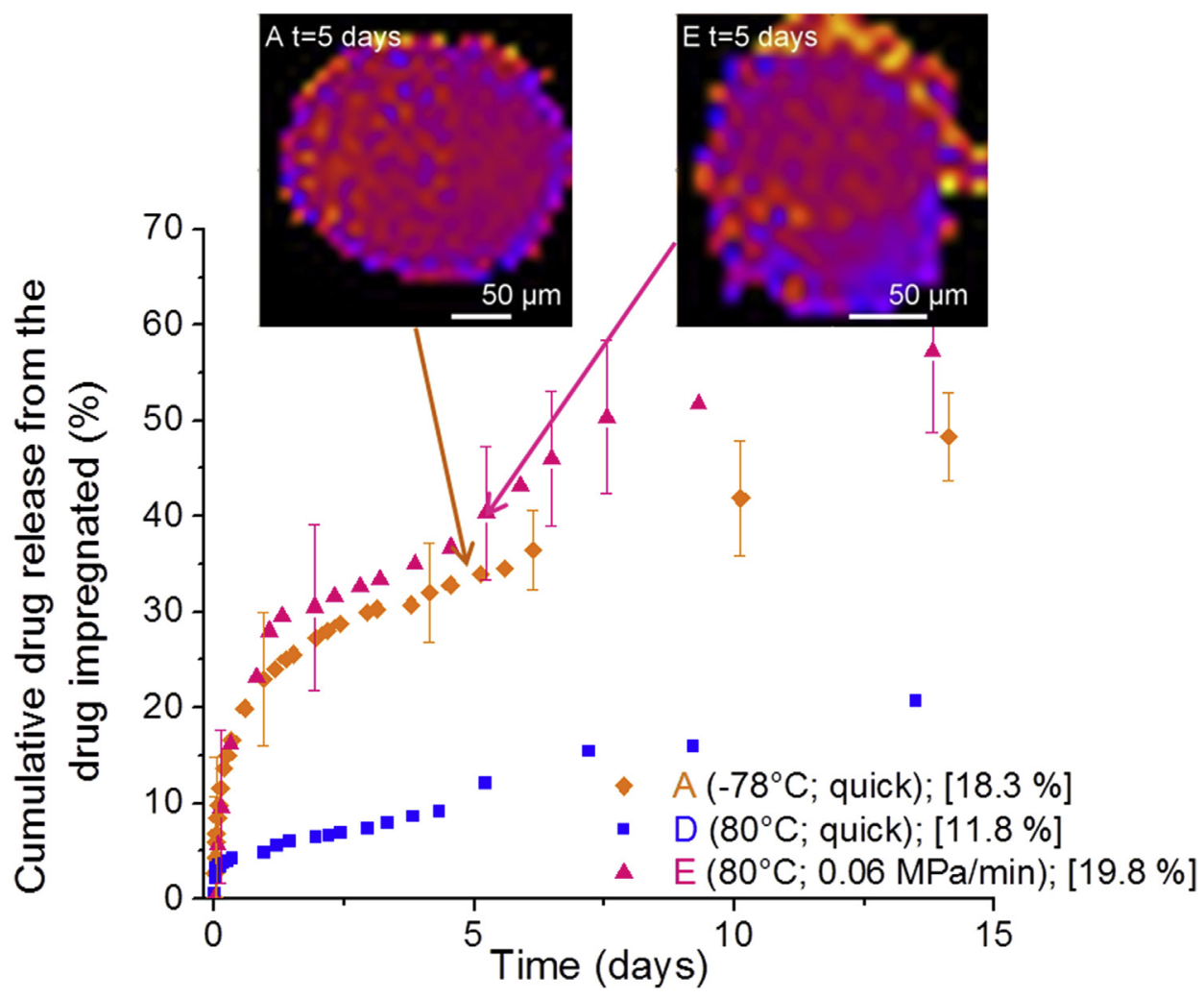

Fig. 9. Release profile due to the drug impregnated into the fiber; comparison of the drug release profiles of fibers A, D and E (in bracket is reported the drug loading).

Table 2

Ketoprofen drug release kinetic parameters obtained from the KorsmeyerPeppas model for samples impregnated varying the depressurization conditions.

\begin{tabular}{llll}
\hline Sample & $n$ & $\mathrm{k}$ & $\mathrm{R}^{2}$ \\
\hline $\mathrm{A}$ & 0.34 & 0.08 & 0.977 \\
$\mathrm{D}$ & 0.82 & 0.006 & 0.99 \\
$\mathrm{E}$ & 0.30 & 0.14 & 0.94 \\
\hline
\end{tabular}

about 3 months due to the progressive degradation of PLLA that facilitates the diffusion of the buffer into the matrix.

\section{Conclusion}

We have evaluated the properties in vitro of sutures made of PLLA impregnated using $\mathrm{scCO}_{2}$ impregnation process with an anti-inflammatory drug, ketoprofen. The objectives of the present study were (i) to evaluate the degradation and the loss of tensile strength in vitro of the absorbable PLLA suture once impregnated with ketoprofen; and (ii) to explore the possibility to tune the drug release of the drug by varying the impregnation and depressurization conditions.

The degradation rate of PLLA was accelerated by the loaded ketoprofen since the carboxylic acid functions of the drug catalyze the hydrolysis of the ester bonds of the matrix. As a consequence, the total loss of tensile strength occurred between 3.5 and 5 weeks making the impregnated PLLA more adapted for suturing tissues that quickly heal.

Varying the impregnation and/or the depressurization conditions, five PLLA sutures were impregnated with ketoprofen. These sutures exhibited various ketoprofen release profile during 3 days to 3 months. A first burst release was observed for all the fibers that is due to the dissolution of a coating made of ketoprofen that precipitated on the suture during the depressurization step. Changing the depressurization conditions enabled to modify the properties of the coating i.e. the amount of drug in the coating and the duration of dissolution (between $5 \mathrm{~min}$ and $5 \mathrm{~h}$ ). The release of ketoprofen impregnated into the suture was governed by two parameters: the free volume of the PLLA matrix and on the degradation rate of the polymer that increases with the amount of drug impregnated inside the suture. The free volume is a function of the depressurization conditions, freezing the reactor before depressurization allows to conserve the volume occupied by $\mathrm{CO}_{2}$ during impregnation whereas a quick depressurization results in a more packed structure. The drug loading is responsible for a higher degradation rate of PLLA which facilitates the ketoprofen release. This exploratory study indicates that the impregnation and depressurization conditions of the $\mathrm{scCO}_{2}$ impregnation process enables to control not only the drug loading but also the drug release from an absorbable matrix.

\section{CRediT authorship contribution statement}

Mathilde Champeau: Conceptualization, Methodology, Investigation, Writing - original draft. Isabela Trindade Coutinho: Writing - original draft. Jean-Michel Thomassin: Methodology, Writing - original draft. Thierry Tassaing: Supervision, Funding acquisition. Christine Jérôme: Supervision, Funding acquisition.

\section{Acknowledgments}

This work was supported by FAPESP, Brazil, process number 2018/ 23902-3. CERM is much indebted to IAP VII-05 "Functional Supramolecular Systems" (FS2). J-M. T. is Logistic Collaborator by the FRS-FNRS. This study was partially financed by the Coordenação de Aperfeiçoamento de Pessoal de Nível Superior - Brasil (CAPES) Finance Code 001, for the master scholarship of I. T. C. 


\section{Appendix A. Supplementary data}

Supplementary data to this article can be found online at https:// doi.org/10.1016/j.jddst.2019.101468.

\section{References}

[1] M. Champeau, J.-M. Thomassin, T. Tassaing, C. Jérôme, Drug loading of polymer implants by supercritical CO2 assisted impregnation: a review, J. Control. Release 209 (2015) 248-259, https://doi.org/10.1016/J.JCONREL.2015.05.002.

[2] B. Bonavoglia, G. Storti, M. Morbidelli, A. Rajendran, M. Mazzotti, Sorption and swelling of semicrystalline polymers in supercritical CO 2, J. Polym. Sci., Part B: Polym. Phys. 44 (2006) 1531-1546, https://doi.org/10.1002/polb.20799.

[3] M. Champeau, J.M. Thomassin, C. Jérôme, T. Tassaing, In situ FTIR micro-spectroscopy to investigate polymeric fibers under supercritical carbon dioxide: CO2sorption and swelling measurements, J. Supercrit. Fluids 90 (2014) 44-52, https://doi.org/10.1016/j.supflu.2014.03.006.

[4] M. Škerget, Z. Knez, M. Knez-Hrnčič, Solubility of solids in sub- and supercritical fluids: a review, J. Chem. Eng. Data 56 (2011) 694-719, https://doi.org/10.1021/ je1011373.

[5] S.G. Kazarian, Supercritical fluid impregnation of polymers for drug delivery, in: P. York, U.B. Kompella, B.Y. Shekunov (Eds.), Supercritical Fluid Technology for Drug Product Development, CRC Press, Boca Raton, 2004, pp. 322-343.

[6] H.C. De Sousa, M.M. Gil, C.M. Duarte, E.B. Leite, A.C. Duarte, Method for preparing therapeutic ophthalmic articles using compressed fluids, US 20060008506, A1 2006.

[7] V.P. Costa, M.E.M. Braga, J.P. Guerra, A.R.C. Duarte, C.M.M. Duarte, E.O.B. Leite, M.H. Gil, H.C. de Sousa, Development of therapeutic contact lenses using a supercritical solvent impregnation method, J. Supercrit. Fluids 52 (2010) 306-316, https://doi.org/10.1016/j.supflu.2010.02.001.

[8] M. Champeau, J.-M. Thomassin, T. Tassaing, C. Jerome, Drug loading of sutures by supercritical $\mathrm{CO}_{2}$ impregnation: effect of polymer/drug interactions and thermal transitions, Macromol. Mater. Eng. 300 (2015) 596-610, https://doi.org/10.1002/ mame.201400369.

[9] K. Sugiura, S. Ogawa, I. Tabata, T. Hori, Impregnation of tranilast to the poly(lactic acid) fiber with supercritical carbon dioxide and the release behavior of tranilast, J. Fiber Sci. Technol. 61 (2005) 159-165, https://doi.org/10.2115/fiber.61.159.

[10] A.M.A. Dias, M.E.M. Braga, I.J. Seabra, P. Ferreira, M.H. Gil, H.C. De Sousa, Development of natural-based wound dressings impregnated with bioactive compounds and using supercritical carbon dioxide, Int. J. Pharm. 408 (2011) 9-19, https://doi.org/10.1016/j.ijpharm.2011.01.063.

[11] A.R.C. Duarte, J.F. Mano, R.L. Reis, Dexamethasone-loaded scaffolds prepared by supercritical-assisted phase inversion, Acta Biomater. 5 (2009) 2054-2062, https:// doi.org/10.1016/j.actbio.2009.01.047.

[12] M.A. Fanovich, J. Ivanovic, D. Misic, M.V. Alvarez, P. Jaeger, I. Zizovic, R. Eggers, Development of polycaprolactone scaffold with antibacterial activity by an integrated supercritical extraction and impregnation process, J. Supercrit. Fluids 78 (2013) 42-53, https://doi.org/10.1016/j.supflu.2013.03.017.

[13] T. Gamse, R. Marr, C. Wolf, K. Lederer, Supercritical CO2 impregnation of polyethylene components for medical purposes, Hem. Ind. 61 (2007) 229-232, https:// doi.org/10.2298/hemind0704229g.

[14] R.W. Greiner, Pharmaceutically impregnated catheters, EP 0405284 A2, 1991.

[15] A. Bouledjouidja, Y. Masmoudi, M. Sergent, E. Badens, Effect of operational conditions on the supercritical carbon dioxide impregnation of anti-inflammatory and antibiotic drugs in rigid commercial intraocular lenses, J. Supercrit. Fluids 130 (2017) 63-75, https://doi.org/10.1016/J.SUPFLU.2017.07.015.

[16] K. Gong, J.A. Darr, I.U. Rehman, Supercritical fluid assisted impregnation of indomethacin into chitosan thermosets for controlled release applications, Int. J. Pharm. 315 (2006) 93-98, https://doi.org/10.1016/j.ijpharm.2006.02.030.

[17] J.P. Yu, Y.X. Guan, S.J. Yao, Z.Q. Zhu, Preparation of roxithromycin-loaded poly(1lactic Acid) films with supercritical solution impregnation, Ind. Eng. Chem. Res. 50 (2011) 13813-13818, https://doi.org/10.1021/ie201294u.

[18] A. Torres, E. Ilabaca, A. Rojas, F. Rodríguez, M.J. Galotto, A. Guarda, C. Villegas, J. Romero, Effect of processing conditions on the physical, chemical and transport properties of polylactic acid films containing thymol incorporated by supercritical impregnation, Eur. Polym. J. 89 (2017) 195-210, https://doi.org/10.1016/J. EURPOLYMJ.2017.01.019.

[19] A. Rojas, D. Cerro, A. Torres, M.J. Galotto, A. Guarda, J. Romero, Supercritical impregnation and kinetic release of 2-nonanone in LLDPE films used for active food packaging, J. Supercrit. Fluids 104 (2015) 76-84, https://doi.org/10.1016/j.supflu. 2015.04.031.

[20] A. Rojas, A. Torres, F. Martínez, L. Salazar, C. Villegas, M.J. Galotto, A. Guarda, J. Romero, Assessment of kinetic release of thymol from LDPE nanocomposites obtained by supercritical impregnation: effect of depressurization rate and nanoclay content, Eur. Polym. J. 93 (2017) 294-306, https://doi.org/10.1016/j.eurpolymj. 2017.05.049.

[21] S. Milovanovic, M. Stamenic, D. Markovic, J. Ivanovic, I. Zizovic, Supercritical impregnation of cellulose acetate with thymol, J. Supercrit. Fluids 97 (2015) 107-115, https://doi.org/10.1016/J.SUPFLU.2014.11.011.

[22] J.M. Anderson, Inflammation, wound healing, and the foreign-body response, in: B.D. Ratner, A.S. Hoffman, F.J. Schoen, J.E. Lemons (Eds.), Biomaterials Science: an Introduction to Biomaterials in Medicine, Elsevier Academic Press, San Diego, 2013, pp. 503-512.

[23] M. Champeau, J.M. Thomassin, C. Jérôme, T. Tassaing, Solubility and speciation of ketoprofen and aspirin in supercritical CO2 by infrared spectroscopy, J. Chem. Eng. Data 61 (2016) 968-978, https://doi.org/10.1021/acs.jced.5b00812.

[24] S. Li, S. Girod-Holland, M. Vert, Hydrolytic degradation of poly(dl-lactic acid) in the presence of caffeine base, J. Control. Release 40 (1996) 41-53, https://doi.org/10. 1016/0168-3659(95)00138-7.

[25] J. Hochberg, G. Murray, Principles of Operative Surgery, fifteenth ed., WB Saunders, Philadelphia, 1992

[26] R.L. Moy, B. Waldman, D.W. Hein, A review of sutures and suturing techniques, J. Dermatol. Surg. Oncol. 18 (1992) 785-795 http://www.ncbi.nlm.nih.gov/pubmed/ 1512311 , Accessed date: 21 March 2019.

[27] S.M. Li, H. Garreau, M. Vert, Structure-property relationships in the case of the degradation of massive aliphatic poly-( $\alpha$-hydroxy acids) in aqueous media - Part 1: poly(dl-lactic acid), J. Mater. Sci. Mater. Med. 1 (1990) 123-130, https://doi.org/ 10.1007/BF00700871.

[28] J. Hochberg, K.M. Meyer, M.D. Marion, Suture choice and other methods of skin closure, Surg. Clin. N. Am. 89 (2009) 627-641, https://doi.org/10.1016/j.suc. 2009.03.001.

[29] A. Pineros-Fernandez, D.B. Drake, P.A. Rodeheaver, D.L. Moody, R.F. Edlich, G.T. Rodeheaver, CAPROSYN*, another major advance in synthetic monofilament absorbable suture, J. Long Term Eff. Med. Implant. 14 (2004) 359-368, https://doi. org/10.1615/JLongTermEffMedImplants.v14.i5.30.

[30] M.E.M. Braga, M.T.V. Pato, H.S.R.C. Silva, E.I. Ferreira, M.H. Gil, C.M.M. Duarte, H.C. de Sousa, Supercritical solvent impregnation of ophthalmic drugs on chitosan derivatives, J. Supercrit. Fluids 44 (2008) 245-257, https://doi.org/10.1016/J. SUPFLU.2007.10.002

[31] X. Ma, D.L. Tomasko, Coating and impregnation of a nonwoven fibrous polyethylene material with a nonionic surfactant using supercritical carbon dioxide, Ind Eng. Chem. Res. 36 (1997) 1586-1597, https://doi.org/10.1021/ie960566p.

[32] D. Singhal, W. Curatolo, Drug polymorphism and dosage form design: a practical perspective, Adv. Drug Deliv. Rev. 56 (2004) 335-347, https://doi.org/10.1016/j addr.2003.10.008.

[33] H.G. Brittain, D.J.R. Grant, P.B. Myrdal, Effects of polymorphism and solid-state solvation on solubility and dissolution rate, in: H.G. Brittain (Ed.), Polymorphism in Pharmaceutical Solids, CRC Press, Boca Raton, 2009, pp. 436-480.

[34] I. Pasquali, R. Bettini, F. Giordano, Supercritical fluid technologies: an innovative approach for manipulating the solid-state of pharmaceuticals, Adv. Drug Deliv. Rev. 60 (2008) 399-410, https://doi.org/10.1016/J.ADDR.2007.08.030.

[35] S.J. Macnaughton, I. Kikic, N.R. Foster, P. Alessi, A. Cortesi, I. Colombo, Solubility of anti-inflammatory drugs in supercritical carbon dioxide, J. Chem. Eng. Data 41 (1996) 1083-1086, https://doi.org/10.1021/je960103q.

[36] K. Florey, Analytical Profiles of Drug Substances and Excipients, first ed., Elsevier Science, New York, 1981.

[37] M. Dixit, P.K. Kulkarni, R.S. Vaghela, Effect of different crystallization techniques on the dissolution behavior of ketoprofen, Trop. J. Pharm. Res. 12 (2013) 317-322, https://doi.org/10.4314/tjpr.v12i3.7.

[38] J. Yu, C. Tang, Y. Guan, S. Yao, Z. Zhu, Sorption and diffusion behavior of carbon dioxide into poly(l-lactic acid) films at elevated pressures, Chin. J. Chem. Eng. 21 (2013) 1296-1302, https://doi.org/10.1016/S1004-9541(13)60623-0.

[39] E. Kiran, Foaming strategies for bioabsorbable polymers in supercritical fluid mixtures. Part I. Miscibility and foaming of poly(l-lactic acid) in carbon dioxide + acetone binary fluid mixtures, J. Supercrit. Fluids 54 (2010) 296-307, https://doi. org /10.1016/j.supflu.2010.05.004.

[40] S.G. Kazarian, M.F. Vincent, F.V. Bright, C.L. Liotta, C.A. Eckert, Specific intermolecular interaction of carbon dioxide with polymers, J. Am. Chem. Soc. 118 (1996) 1729-1736, https://doi.org/10.1021/ja950416q.

[41] M.A. Fanovich, P. Jaeger, Sorption and diffusion of compressed carbon dioxide in polycaprolactone for the development of porous scaffolds, Mater. Sci. Eng. C 32 (2012) 961-968, https://doi.org/10.1016/j.msec.2012.02.021.

[42] M. Champeau, J.-M. Thomassin, C. Jérôme, T. Tassaing, In situ investigation of supercritical $\mathrm{CO}_{2}$ assisted impregnation of drugs into a polymer by high pressure FTIR micro-spectroscopy, Analyst 140 (2015) 869-879, https://doi.org/10.1039/ C4AN01130A.

[43] P.L. Ritger, N.A. Peppas, A simple equation for description of solute release I. Fickian and non-fickian release from non-swellable devices in the form of slabs, spheres, cylinders or discs, J. Control. Release 5 (1987) 23-36, https://doi.org/10 1016/0168-3659(87)90034-4. 